\title{
Effects of High-Dose Rosuvastatin on Ventricular Remodelling and Cardiac Function in ST-Segment Elevation Myocardial Infarction
}

This article was published in the following Dove Press journal: Drug Design, Development and Therapy

\author{
Rong Luo* \\ Xiaochen Sun ${ }^{*}$ \\ Feiyan Shen \\ Bin Hong \\ Zilong Wang
}

Department of Cardiology, Qingpu Medical Center, Zhongshan Hospital, Fudan University, Shanghai, People's Republic of China

*These authors contributed equally to this work
Correspondence: Zilong Wang

Email wangthinker|23@outlook.com
Objective: To investigate the effects of high-dose rosuvastatin on ventricular remodelling and cardiac function in ST-segment elevation myocardial infarction (STEMI).

Materials and Methods: From January 2017 to March 2019, the clinical data of 93 patients with STEMI were collected and analysed, with 46 cases in the conventional-dose group (rosuvastatin, $10 \mathrm{mg} / \mathrm{d}$ ) and 47 cases in the high-dose group (rosuvastatin, $20 \mathrm{mg} / \mathrm{d}$ ). Blood lipid (TC, TG, LDL-C and HDL-C), serum inflammatory markers (hs-CRP, IL-6, TNF- $\alpha$ and ICAM-1), ventricular remodelling markers (NT-pro BNP, MMP-9, TIMP-4 and Gal-3) and indicators of cardiac function (LVESD, LVESD, LVESV, LVEDV, IVST and LVEF) were collected from all patients at the time of admission and 8 weeks after rosuvastatin treatment.

Results: After treatment with rosuvastatin for 8 weeks, compared with those in conventional-dose group, the levels of TC, TG, LDL-C, hs-CRP, IL-6, TNF- $\alpha$, ICAM-1, NT-pro BNP, MMP-9 and Gal-3 in the high-dose group decreased significantly $(\mathrm{P}<0.05)$, while the increase of HDL-C and TIMP-4 levels was more obvious $(\mathrm{P}<0.05)$ than that in the conventional-dose group. Moreover, LVEF was significantly higher $(\mathrm{P}<0.05)$ and LVESD, LVESD, LVESV, LVEDV and IVST were significantly lower $(\mathrm{P}<0.05)$ after treatment than before treatment in both groups. The improvement of cardiac ultrasound results in the high-dose group was more significant than that in the conventional-dose group $(\mathrm{P}<0.05)$.

Conclusion: This study suggests that high-dose rosuvastatin was better than conventionaldose rosuvastatin for improving blood lipid metabolism, reducing the inflammatory response, and preventing and treating ventricular remodelling and myocardial fibrosis, indicating that high-dose rosuvastatin had stronger therapeutic effect on STEMI than conventional-dose rosuvastatin.

Keywords: rosuvastatin, ST elevation myocardial infarction, blood lipids, inflammatory factor, ventricular remodelling, myocardial fibrosis

\section{Introduction}

ST elevation myocardial infarction (STEMI) is a serious type of coronary heart disease, which is a major cause of disability and death. ${ }^{1,2}$ Under atherosclerotic conditions, STEMI usually results in plaque rupture, platelet aggregation and coronary artery occlusion due to agitation, overwork, excessive drinking and overeating. ${ }^{1,3}$ STEMI can activate many humoura factors, reduce the number of myocardial cells and fibrosis of myocardial interstitium, which leads to ventricular diastolic dysfunction and poor ventricular remodelling. ${ }^{4,5}$ Ventricular remodelling is 
an important factor in determining cardiac function and prognosis after myocardial infarction. How to prevent and treat myocardial fibrosis, reverse ventricular remodelling, improve cardiac function, reduce the mortality of patients, has been the focus of clinical staff.

Statins are the main therapeutic drugs for patients with acute myocardial infarction. These drugs can significantly reduce the morbidity and mortality of patients with cardiovascular disease by reducing plasma cholesterol and atherosclerotic plaque-mediated inflammation. ${ }^{6-8}$ Clinical studies have proven that statins not only regulate lipids but also improve myocardial fibrosis, regulate ventricular remodelling, regulate cell proliferation and apoptosis, and protect the myocardium. ${ }^{6-8}$ Rosuvastatin is a new type of hydrophilic statin. Ninety percent of rosuvastatin is metabolized through intestine or kidney. Compared with simvastatin and atorvastatin, which are metabolized by CYP4503A4, rosuvastatin, which is used in combination with other commonly used cardiovascular drugs such as clopidogrel or warfarin, has a lower possibility of interactions and a higher bioavailability. ${ }^{9,10}$ It has been suggested that rosuvastatin can inhibit atherosclerotic plaque and inflammation, reduce cardiovascular adverse events and effectively prevent myocardial infarction. ${ }^{9,10}$ However, there are few reports about the effects of different doses of rosuvastatin on myocardial fibrosis and ventricular remodelling in patients with STEMI. In this study, different doses of rosuvastatin were used to treat patients with STEMI. The effects of rosuvastatin on blood lipid (TC, TG, LDL-C and HDL-C), serum inflammatory markers (hs-CRP, IL-6, TNF- $\alpha$ and ICAM-1), ventricular remodelling markers (NT-pro BNP, MMP-9, TIMP-4 and Gal-3) and cardiac function (LVESD, LVESD, LVESV, LVEDV, IVST and LVEF) in patients with STEMI were observed. The purpose of this study was to explore the effect of rosuvastatin on ventricular remodelling and cardiac function after myocardial infarction.

\section{Materials and Methods}

\section{Clinical Patients and Drug Intervention}

From January 2017 to March 2019, the clinical data of 93 patients with STEMI were collected and analysed, with 46 cases in the conventional-dose group (rosuvastatin, $10 \mathrm{mg} / \mathrm{d}$ ) and 47 cases in the high-dose group (rosuvastatin, $20 \mathrm{mg} / \mathrm{d}$ ). The diagnosis of STEMI was confirmed according to the European Heart Association Guidelines. ${ }^{11}$ Inclusion criteria were as follows: electrocardiogram showed abnormal elevation of the ST segment; first myocardial infarction occurred; the patients received one-stage percutaneous coronary intervention (PCI) therapy within $12 \mathrm{~h}$; there was no history of severe allergy and other organ diseases; there was no familial hypercholesterolemia; and in the first 2 weeks of hospital stay, no antilipidaemic and antioxidant drugs were used. The exclusion criteria were as follows: severe cardiac insufficiency; hepatic insufficiency (continuous increase of serum transaminase more than 3 times of the upper limit of normal level) or renal insufficiency (creatinine clearance rate $<30 \mathrm{~mL} / \mathrm{min}$ ); use of blood lipid lowering and antioxidant drugs in the first 2 weeks of hospital stay; familial hypercholesterolemia; malignant tumour; immune system disease; acute infectious disease; serious blood system disease; and prohibition of rosuvastatin.

PCI was described in the previous literature. ${ }^{12}$ Patients after PCI were randomly assigned to the conventional-dose group and the =high-dose group. The conventional dose group received rosuvastatin at $10 \mathrm{mg} / \mathrm{d}$ and the -high-dose group received rosuvastatin at $20 \mathrm{mg} / \mathrm{d}$. In addition to the statins treatment, according to the opinion of European Heart Association guidelines, ${ }^{13}$ the two groups were treated with aspirin, clopidogrel, anticoagulants, $\beta$ receptor blocker, angiotensin-converting enzyme inhibitor (ACE-I) or angiotensin receptor blocker (ARB). After starting rosuvastatin treatment, all patients had a standard low cholesterol diet, and maintained a reasonable diet throughout the treatment period. The study was performed in accordance with the ethical standards of the institutional and national research committee and with the 1964 Helsinki Declaration and its later amendments or comparable ethical standards. The study was approved by the ethics committee of Fudan University and all participants signed informed consent.

\section{Detection of Blood Observation Indexes}

Venous blood was drawn from all patients at the time of admission and 8 weeks after rosuvastatin treatment. Total cholesterol (TC), triglycerides (TGs), low-density lipoprotein cholesterol (LDL-C) and high-density lipoprotein cholesterol (HDL-C) were measured by Olympus (Japan) automatic biochemical analyser. High-sensitivity $\mathrm{C}$ reactive protein (hs-CRP), interleukin-6 (IL-6), tumour necrosis factor $\alpha$ (TNF- $\alpha)$, intercellular cell adhesion molecule-1 (ICAM-1), N-terminal brain natriuretic peptide precursor (NT-pro BNP), matrix metalloproteinase-9 (MMP-9), matrix metalloproteinase inhibitor 4 (TIMP-4) and galectin-3 (Gal3) were measured by ELISAs using immunoassay kit (Becton, Dickinson and Company, USA). 


\section{Cardiac Echocardiography}

Colour Doppler echocardiography was performed by a qualified ultrasound specialist who was blinded to the patient information. Colour Doppler echocardiography was used to detect the left ventricular end systolic diameter (LVESD), left ventricular end-diastolic diameter (LVEDD), left ventricular end-systolic volume (LVESV), left ventricular end-diastolic volume (LVEDV), interventricular septum thickness (IVST) and left ventricular ejection fraction (LVEF) of the two groups before and 8 weeks after treatment.

\section{Statistical Analysis}

SPSS 19.0 software was used for data analysis. The results are expressed as the mean \pm standard deviation $(\mathrm{x} \pm \mathrm{s})$. Baseline characteristics, as well as post treatment changes, were compared between groups and within two groups. A chi-squared test or Fisher's exact test was used for the analysis of contingency tables depending on the sample size. Student's $t$ test and the Wilcoxon test were used to compare clinical characteristics between the conventional-dose group and the high-dose group, while parametric variables were compared by using paired t-tests within groups. $\mathrm{P}<0.05$ was considered as statistically significant for all tests.

\section{Result}

\section{Baseline Characteristics}

Ninety-three patients were included in the study (conventional-dose group, $n=46$, high-dose group, $n=47$ ). During the 8-week drug treatment, there were no patients who stopped the treatments due to adverse drug reactions. As shown in Table 1, there was no significant difference in age, gender, comorbidity, Gensini score, and liver and kidney function between the two groups, and the clinical baseline data of the two groups were comparable $(\mathrm{P}>0.05)$.

\section{Changes in Blood Lipids and Serum Inflammatory Factors}

As shown in Tables 2 and 3, before treatment, there was no significant difference in the blood lipids (TC, TGs, LDL-C and HDL-C) and inflammatory markers (hs-CRP, IL-6, TNF- $\alpha$ and ICAM-1) between the two groups ( $\mathrm{P}>0.05)$. After treatment with rosuvastatin for 8 weeks, the serum TC $(\mathrm{P}<0.05)$, TG $(\mathrm{P}<0.05)$, LDL-C $(\mathrm{P}<0.05)$, hs-CRP $(\mathrm{P}<0.05)$, IL-6 $(\mathrm{P}<0.05)$, TNF- $\alpha(\mathrm{P}<0.05)$ and ICAM-1 $(\mathrm{P}<0.05)$ levels of the two groups decreased significantly, while the HDL-C level $(\mathrm{P}<0.05)$ increased significantly. Compared with those of the conventional-dose group, the levels of TC $(5.07 \pm 0.35$ vs $5.87 \pm 0.39, \mathrm{P}<0.05)$, TG $(1.13$ \pm 0.25 vs $1.41 \pm 0.31, \mathrm{P}<0.05)$, LDL-C $(1.89 \pm 0.29$ vs 2.53 $\pm 0.35, \mathrm{P}<0.05)$, hs-CRP $(2.78 \pm 0.96$ vs $3.33 \pm 0.75, \mathrm{P}<$ $0.05)$, IL-6 (95.62 \pm 28.14 vs $130.05 \pm 43.78, \quad \mathrm{P}<0.05)$, TNF- $\alpha(4.43 \pm 0.98$ vs $5.53 \pm 1.11, \mathrm{P}<0.05)$ and ICAM-1 $(316.98 \pm 64.22$ vs $375.87 \pm 63.69, \mathrm{P}<0.05)$ in the high-dose group decreased significantly, while the increase of HDLC level $(2.86 \pm 0.19$ vs $2.56 \pm 0.25, \mathrm{P}<0.05)$ was more obvious. These results suggest high-dose rosuvastatin can significantly reduce blood lipids and has anti-inflammatory effects.

\section{Changes in Ventricular Remodelling and Myocardial Fibrosis Index}

As shown in Table 4, there was no significant difference in NT-Pro BNP, Gal-3, MMP-9 and TIMP-4 between the two groups before treatment $(\mathrm{P}>0.05)$. After treatment with

Table I Clinical Characteristics of Baseline Before Treatment in Two Groups

\begin{tabular}{|l|l|l|l|}
\hline Parameter & Convenient-Dose Group (n=46) & High-Dose Group (n=47) & P value \\
\hline Age, years & $59.91 \pm 6.67$ & $60.64 \pm 5.02$ & $0.556^{*}$ \\
Gender, M/F (n, \%) & $31 / 15(67 / 33)(67 / 33)$ & $33 / 14(70 / 30)$ & $0.34 I^{*}$ \\
Hypertension (n, \%) & $19(4 I)$ & $22(46)$ & $0.143^{*}$ \\
Diabetes mellitus (n, \%) & $12(26)$ & $15(31)$ & $0.749^{*}$ \\
Smoking (\%) & $20(43)$ & $23(48)$ & $0.612^{*}$ \\
Gensini score & $107 \pm 40$ & $96 \pm 34$ & $0.150^{\#}$ \\
FBS (mg/dL) & $5.99 \pm 1.76$ & $5.51 \pm 1.87$ & $0.204^{\#}$ \\
ALT, (U/L) & $30.32 \pm 9.40$ & $30.61 \pm 8.98$ & $0.879^{\#}$ \\
AST,(U/L) & $31.93 \pm 8.91$ & $29.40 \pm 9.57$ & $0.19 I^{\#}$ \\
Serum creatinine ( $\mu \mathrm{mol} / \mathrm{L})$ & $81.84 \pm 14.26$ & $79.27 \pm 13.55$ & $0.375^{\#}$ \\
Serum urea (mmol/L) & $4.37 \pm 1.31$ & $4.50 \pm 1.32$ & $0.657^{\#}$ \\
\hline
\end{tabular}

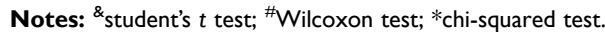

Abbreviations: ALT, alanine aminotransferase; AST, aspartate aminotransferase; FBS, fasting blood glucose. 
Table 2 Changes of Blood Lipid Levels Before and After Treatment in Two Groups

\begin{tabular}{|l|l|l|l|l|l|}
\hline Parameter & & TC $(\mathbf{m m o l} / \mathbf{L})$ & TG $(\mathbf{m m o l} / \mathbf{L})$ & LDL-C (mmol/L) & HDL-C A (mmol/L) \\
\hline Conventional-dose group $(\mathrm{n}=46)$ & $\begin{array}{l}\text { Before treatment } \\
\text { 8th week of the therapy }\end{array}$ & $\begin{array}{l}7.61 \pm 0.4 \mathrm{I} \\
5.87 \pm 0.39^{\mathrm{a}}\end{array}$ & $\begin{array}{l}1.75 \pm 0.34 \\
1.41 \pm 0.3 \mathrm{I}^{\mathrm{a}}\end{array}$ & $\begin{array}{l}3.52 \pm 0.36 \\
2.53 \pm 0.35^{\mathrm{a}}\end{array}$ & $\begin{array}{l}2.17 \pm 0.3 \mathrm{I} \\
2.56 \pm 0.25^{\mathrm{a}}\end{array}$ \\
\hline High-dose group $(\mathrm{n}=47)$ & Before treatment & $7.46 \pm 0.47$ & $1.77 \pm 0.34$ & $3.69 \pm 0.39$ & $2.21 \pm 0.25$ \\
& 8th week of the therapy & $5.07 \pm 0.35^{\mathrm{a}, \mathrm{b}}$ & $1.13 \pm 0.25^{\mathrm{a}, \mathrm{b}}$ & $1.89 \pm 0.29^{\mathrm{a}, \mathrm{b}}$ & $2.86 \pm 0.19^{\mathrm{a}, \mathrm{b}}$ \\
\hline
\end{tabular}

Notes: Data are presented as means $\pm S D$. ${ }^{a}$ indicates a significant difference compared Before treatment $(\mathrm{P}<0.05)$. ${ }^{\mathrm{b}}$ indicates a significant difference compared Conventionaldose group $(P<0.05)$. Paired student's $t$ test was used before and after treatment, and Wilcoxon test was used between groups.

Abbreviations: HDL-C, high-density lipoprotein cholesterol; LDL-C, low-density lipoprotein cholesterol; TC, total cholesterol, TG, triglyceride.

Table 3 Changes of Serum Inflammatory Factors Levels Before and After Treatment in Two Groups

\begin{tabular}{|l|l|l|l|l|l|}
\hline Parameter & & hs-CRP $(\mathbf{m m o l} / \mathbf{L})$ & IL-6 (pg/mL) & TNF- $\alpha(\mathbf{p g} / \mathbf{m L})$ & ICAM-I $(\mu g / L)$ \\
\hline Conventional-dose group $(\mathrm{n}=46)$ & $\begin{array}{l}\text { Before treatment } \\
\text { 8th week of the therapy }\end{array}$ & $\begin{array}{l}8.31 \pm 0.8 \mathrm{I} \\
3.33 \pm 0.75^{\mathrm{a}}\end{array}$ & $\begin{array}{l}353.51 \pm 45.68 \\
130.05 \pm 43.78^{\mathrm{a}}\end{array}$ & $\begin{array}{l}16.29 \pm 4.26 \\
5.53 \pm 1 . \mathrm{II}^{\mathrm{a}}\end{array}$ & $\begin{array}{l}567.52 \pm 94.15 \\
375.87 \pm 63.69^{\mathrm{a}}\end{array}$ \\
\hline High-dose group $(\mathrm{n}=47)$ & $\begin{array}{l}\text { Before treatment } \\
\text { 8th week of the therapy }\end{array}$ & $\begin{array}{l}8.24 \pm 0.88 \\
2.78 \pm 0.96^{\mathrm{a}, \mathrm{b}}\end{array}$ & $\begin{array}{l}366.27 \pm 50.43 \\
95.62 \pm 28.14^{\mathrm{a}, \mathrm{b}}\end{array}$ & $\begin{array}{l}17.10 \pm 4.13 \\
4.43 \pm 0.98^{\mathrm{a}, \mathrm{b}}\end{array}$ & $\begin{array}{l}574.5 I \pm 85.75 \\
316.98 \pm 64.22^{\mathrm{a}, \mathrm{b}}\end{array}$ \\
\hline
\end{tabular}

Notes: Data are presented as means $\pm S D$. ${ }^{a}$ indicates a significant difference compared before treatment $(P<0.05)$. ${ }^{b}$ indicates a significant difference compared conventionaldose group $(P<0.05)$. Paired student's $t$ test was used before and after treatment, and Wilcoxon test was used between groups.

Abbreviations: hs-CRP, high sensitive C reactive protein; ICAM-I, intercellular cell adhesion molecule-I; IL-6, interleukin-6; TNF- $\alpha$, tumor necrosis factor $\alpha$.

Table 4 Changes of Ventricular Remodeling and Myocardial Fibrosis Markers Levels Before and After Treatment in Two Groups

\begin{tabular}{|l|l|l|l|l|l|}
\hline Parameter & & NT-pro BNP $(\mathbf{p g} / \mathbf{m L})$ & $\mathbf{G a l - 3}(\mathbf{n g} / \mathbf{m L})$ & TIMP-4 $(\mu \mathrm{g} / \mathbf{L})$ & MMP-9 $(\mu \mathbf{g} / \mathbf{L})$ \\
\hline Conventional-dose group $(\mathrm{n}=46)$ & $\begin{array}{l}\text { Before treatment } \\
\text { 8th week of the therapy }\end{array}$ & $\begin{array}{l}687.62 \pm 133.34 \\
241.22 \pm 38.7 I^{\mathrm{a}}\end{array}$ & $\begin{array}{l}7.44 \pm 1.25 \\
3.87 \pm 0.34^{\mathrm{a}}\end{array}$ & $\begin{array}{l}51.46 \pm 4.42 \\
72.71 \pm 7.10^{\mathrm{a}}\end{array}$ & $\begin{array}{l}366.93 \pm 62.45 \\
238.83 \pm 35.85^{\mathrm{a}}\end{array}$ \\
\hline High-dose group $(\mathrm{n}=47)$ & $\begin{array}{l}\text { Before treatment } \\
\text { 8th week of the therapy }\end{array}$ & $\begin{array}{l}631.46 \pm 165.27 \\
194.39 \pm 44.08^{\mathrm{a}, \mathrm{b}}\end{array}$ & $\begin{array}{l}7.80 \pm 1.39 \\
2.90 \pm 0.28^{\mathrm{a}, \mathrm{b}}\end{array}$ & $\begin{array}{l}50.77 \pm 4.04 \\
82.46 \pm 6.95^{\mathrm{a}, \mathrm{b}}\end{array}$ & $\begin{array}{l}377.18 \pm 55.67 \\
184.55 \pm 42.09^{\mathrm{a}, \mathrm{b}}\end{array}$ \\
\hline
\end{tabular}

Notes: Data are presented as means $\pm S D$. ${ }^{a}$ indicates a significant difference compared Before treatment $(\mathrm{P}<0.05)$. ${ }^{\mathrm{b}}$ indicates a significant difference compared Conventionaldose group $(P<0.05)$. Paired student's $t$ test was used before and after treatment, and Wilcoxon test was used between groups.

Abbreviations: MMP-9, matrix metalloproteinase-9; Gal-3, galectin-3; NT-pro BNP, N-terminal brain natriuretic peptide precursor; TIMP-4, matrix metalloproteinase inhibitor 4 .

rosuvastatin for 8 weeks, the serum NT-Pro BNP $(\mathrm{P}<$ 0.05), Gal-3 $(\mathrm{P}<0.05)$ and MMP-9 $(\mathrm{P}<0.05)$ levels of the two groups decreased significantly, while TIMP-4 $(\mathrm{P}<$ $0.05)$ increased significantly. Compared with those of the conventional-dose group, the levels of NT-Pro BNP (194.39 \pm 44.08 vs $241.22 \pm 38.71, \mathrm{P}<0.05)$, Gal-3 $(2.90$ \pm 0.28 vs $3.87 \pm 0.34, \mathrm{P}<0.05)$ and MMP-9 $(184.55 \pm 42.09$ vs $238.83 \pm 35.85, \quad \mathrm{P}<0.05)$ in the high-dose group decreased significantly, while the increase of TIMP-4 level $(82.46 \pm 6.95$ vs $72.71 \pm 7.10, \mathrm{P}<0.05)$ was more obvious. These results that high-dose rosuvastatin can significantly improve ventricular remodelling.

\section{Echocardiographic Changes}

As shown in Table 5, there was no significant difference in LVESD, LVESD, LVESV, LVEDV, IVST and LVEF between the two groups before treatment $(\mathrm{P}>0.05)$. After treatment with rosuvastatin for 8 weeks, echocardiography showed that LVEF $(\mathrm{P}<0.05)$ was significantly higher and LVESD $(\mathrm{P}<0.05)$, LVESD $(\mathrm{P}<0.05)$, LVESV $(\mathrm{P}<0.05)$, LVEDV $(\mathrm{P}<0.05)$ and IVST $(\mathrm{P}<0.05)$ were significantly lower than those before treatment. Compared with those of the conventional-dose group, the level of the LVEF (57.62 \pm 7.76 vs $52.52 \pm 6.28, \mathrm{P}<0.05)$ increase and the LVESD (30.01 \pm 4.97 vs $34.36 \pm 5.05, \mathrm{P}<0.05)$, LVESD $(42.42 \pm 7.69$ vs $49.96 \pm 8.41, \mathrm{P}<0.05)$, LVESV (46.11 \pm 7.74 vs 51.84 $\pm 9.73, \mathrm{P}<0.05)$, LVEDV (85.63 \pm 9.14 vs $89.85 \pm 8.49, \mathrm{P}<$ $0.05)$ and IVST $(9.75 \pm 2.01$ vs $11.26 \pm 1.73, \mathrm{P}<0.05)$ decreases in the high-dose group were significantly greater, the difference was statistically significant. These results suggest that high-dose rosuvastatin can significantly improve ventricular remodeling. 
Table 5 Changes of Echocardiography Results Before and After Treatment in Two Groups

\begin{tabular}{|l|l|l|l|l|}
\hline Parameter & \multicolumn{3}{|l|}{ Conventional-Dose Group $(\mathbf{n = 4 6 )}$} & \multicolumn{2}{l|}{ High-Dose Group (n=47) } \\
\hline & Before treatment & 8 th week of the therapy & Before treatment & 8 th week of the therapy \\
LVESD $(\mathrm{mm})$ & $42.05 \pm 5.67$ & $34.36 \pm 5.05^{\mathrm{a}}$ & $43.75 \pm 6.68$ & $30.01 \pm 4.97^{\mathrm{a}, \mathrm{b}}$ \\
LVEDD $(\mathrm{mm})$ & $60.38 \pm 6.84$ & $49.96 \pm 8.41^{\mathrm{a}}$ & $61.32 \pm 7.46$ & $42.42 \pm 7.69^{\mathrm{a}, \mathrm{b}}$ \\
LVESV $(\mathrm{mL})$ & $63.20 \pm 8.83$ & $51.84 \pm 9.73^{\mathrm{a}}$ & $61.35 \pm 10.46$ & $46.11 \pm 7.74^{\mathrm{a}, \mathrm{b}}$ \\
LVEDV $(\mathrm{mL})$ & $114.44 \pm 15.50$ & $89.85 \pm 8.49^{\mathrm{a}}$ & $112.56 \pm 13.95$ & $85.63 \pm 9.14^{\mathrm{a}, \mathrm{b}}$ \\
IVST $(\mathrm{mm})$ & $14.76 \pm 1.67$ & $11.26 \pm 1.73^{\mathrm{a}}$ & $14.28 \pm 1.57$ & $9.75 \pm 2.01^{\mathrm{a}, \mathrm{b}}$ \\
LVEF $(\%)$ & $43.48 \pm 6.96$ & $52.52 \pm 6.28^{\mathrm{a}}$ & $42.65 \pm 7.24$ & $57.62 \pm 7.76^{\mathrm{a}, \mathrm{b}}$ \\
\hline
\end{tabular}

Notes: Data are presented as means \pm SD. ${ }^{a}$ indicates a significant difference compared Before treatment $(P<0.05)$. ${ }^{b}$ indicates a significant difference compared conventionaldose group $(P<0.05)$. Paired student's $t$ test was used before and after treatment, and Wilcoxon test was used between groups.

Abbreviations: IVST, interventricular septum thickness; LVESD, left ventricular end-systolic diameter; LVEDD, left ventricular end-diastolic diameter; LVESV, left ventricular end-systolic volume; LVEDV, left ventricular end-diastolic volume; LVEF, left ventricular ejection fraction.

\section{Discussion}

Rosuvastatin is a new type of statin. The commonly used dose is $10 \mathrm{mg} / \mathrm{d}$. Rosuvastatin is metabolized through intestine or kidney. Compared with simvastatin and atorvastatin metabolized through CYP4503A4, rosuvastatin shows the strongest lipid-lowering effect and its safety is better than any other statin. ${ }^{9,10,14-16}$ At present, the study of high-dose rosuvastatin in the treatment of coronary heart disease has confirmed that rosuvastatin can improve the therapeutic effect without increasing adverse reactions. ${ }^{17,18}$ In this study, compared with the conventional-dose group (10 mg/ d), high-dose rosuvastatin $(20 \mathrm{mg} / \mathrm{d})$ was superior to lowdose rosuvastatin in improving blood lipid, serum inflammatory factors, myocardial fibrosis-related factors and cardiac function indexes in patients with STEMI. The results suggest that $20 \mathrm{mg} / \mathrm{d}$ of rosuvastatin can significantly improve blood lipids levels, reduce the inflammatory response, and improve ventricular remodelling and cardiac function in patients with STEMI.

Lipoprotein metabolic disorder is an independent risk factor for coronary heart disease, in which the levels of TC, TG, LDL-C are increased, and the decrease in HDL-C level is closely related to the occurrence and development of myocardial infarction. ${ }^{18-20}$ Among all statins, rosuvastatin most significantly regresses and reverses atherosclerosis, increases HDL-C and lowers LDL-C levels. ${ }^{8,21}$ Previous studies reported that the differences between rosuvastatin at 20 and $10 \mathrm{mg}$ are usually relatively modest $(50 \%$ and $45 \%$ LDL-C decrease, respectively) in acute coronary syndrome subjects. ${ }^{22,23}$ However, in this study, we found that the levels of TC, TG and LDL-C in the two groups after treatment were significantly lower than those before treatment, and the levels of HDL-C were significantly higher than those before treatment. Furthermore, the improvement in blood lipid levels in the high-dose group was more significant than that in the conventional-dose group $(\mathrm{P}<0.05)$, indicating that the highdose $(20 \mathrm{mg} / \mathrm{d})$ could significantly improve the blood lipid levels of STEMI patients. The results of our study are similar to those previously reported, but we found that high-dose rosuvastatin $(20 \mathrm{mg} / \mathrm{d})$ had stronger lipid-lowering effects than low-dose rosuvastatin $(10 \mathrm{mg} / \mathrm{d})$, which may be caused by different ethnic groups, disease conditions and treatment times. In recent years, inflammatory processes have been shown to play an important role in the occurrence of cardiovascular events, and the anti-inflammatory effect of statins has attracted increased people's attention. ${ }^{6,7,24}$ hs-CRP is mainly secreted by hepatocytes and plays a very important role in the occurrence, development and prognosis of acute myocardial infarction. ${ }^{25,26}$ Increasing levels of hs-CRP promote foam cell formation, inflammatory cell infiltration, and disruption of vascular endothelial cell function, thereby increasing atherosclerotic plaque instability. ${ }^{25-27}$ IL-6 and TNF- $\alpha$ are inflammatory cytokines secreted by activated mononuclear/macrophage cells. In myocardial infarction, the persistent increased expression of IL- 6 and TNF- $\alpha$ has a direct toxic effect on the ischaemic myocardium. This change can accelerate the apoptosis and necrosis of myocardial cells, stimulate the secretion of endostatin by endothelial cells and inhibit the synthesis of thrombomodulin, resulting in the aggravation of myocardial infarction injury. ${ }^{28-31}$ Current research shows that there is inflammatory cell aggregation around the infarcted myocardium in patients with myocardial infarction, and an important factor causing inflammatory cell aggregation is intercellular cell adhesion molecule-1 (ICAM-1). ${ }^{30,31}$ ICAM-1 can bind neutrophils to the myocardium, release cytotoxic substances, and damage myocardial cells. ${ }^{30,31}$ A previous study showed that reducing the level of inflammatory factors (hs-CRP, IL-6, TNF- $\alpha$ and 
ICAM-1) in patients with myocardial infarction can stabilize atheromatous plaques, improve endothelial function, reduce myocardial cell apoptosis, and retard slowdown or even reverse ventricular remodelling. ${ }^{24-31}$ In this study, the levels of hs-CRP, IL-6, TNF- $\alpha$ and ICAM-1 were significantly reduced in the two groups after treatment with rosuvastatin. Compared with those of conventional-dose group, the levels of hs-CRP, IL-6, TNF- $\alpha$ and ICAM-1 were significantly lower in the high-dose group $(\mathrm{P}<0.05)$. This result suggests that $20 \mathrm{mg} / \mathrm{d}$ of rosuvastatin is more effective in improving the level of inflammatory indicators and inhibiting the inflammatory response than the low dose.

Studies have shown that ventricular remodelling is closely related to matrix metalloproteinase (MMPs), tissue inhibitors of metalloproteinases (TIMPs), Gal-3 and NTpro BNP. MMPs are the only enzymes that can degrade extracellular matrix and TIMPs are natural inhibitors of MMPs. The MMPs/TIMPs balance is the key to maintaining the balance of collagen synthesis and degradation in cardiac fibroblasts. If the activity of MMPs (especially MMP-9) is excessively increased or the activity of TIMPs (especially TIMP-4) is excessively reduced, ventricular remodelling and myocardial fibrosis will occur. $^{32-35}$

Gal-3 belongs to the galectin family. Gal-3 inhibits the degradation of extracellular matrix by MMPs and TIMPs, resulting in hyperplasia of cardiac fibroblasts and increased collagen synthesis. Gal-3 is a biomarker of heart failure and myocardial fibrosis. ${ }^{36,37}$ NT-Pro BNP is mainly from the ventricles and the release of NT-Pro BNP is positively proportional to the infarct area and the degree of cardiac dysfunction, which has important clinical value for the detection of cardiac function and prognosis. ${ }^{38,39}$ NT-pro BNP and LVESD, LVESD, LVESV, LVEDV, IVST and LVEF are good indicators of cardiac function. When NT-pro BNP, LVESD, LVESD, LVESV, LVEDV, IVST and LVEF exceed normal values, there is a possibility of heart failure. ${ }^{38-41}$ In this study, the TIMP-4 levels were significantly elevated in both groups after treatment with rosuvastatin, while the MMP-9, Gal-3, and NT-pro BNP levels were significantly decreased. Compared with those of the conventional-dose group, TIMP-4 increased and MMP-9, Gal-3, NT Pro BNP decreased significantly in the high-dose group $(\mathrm{P}<0.05)$. This finding suggests that $20 \mathrm{mg} / \mathrm{d}$ rosuvastatin is better than the low dose in preventing and treating ventricular remodelling and myocardial fibrosis. We also observed the effect of rosuvastatin via colour Doppler echocardiography of patients with STEMI. Our study found that LVEF was significantly higher and LVESD, LVESD, LVESV, LVEDV, and IVST were significantly lower than those before treatment in both groups after treatment with rosuvastatin. Compared with that of the conventional-dose group, the improvement of the cardiac ultrasound results in the high-dose group was more significant $(\mathrm{P}<0.05)$. This result suggests that $20 \mathrm{mg} / \mathrm{d}$ of rosuvastatin is better than the low dose in improving cardiac function. There are some limitations in this study. First, this study is a small sample single centre study, and the conclusions are thus limited. Second, the population included in this study was a cohort with STEMI, and the data of non-STEMI patients were not described. Third, we only observed the effect of rosuvastatin on ventricular remodelling for 8 weeks in this study. The effect of rosuvastatin over 8 weeks on ventricular remodelling has not been elucidated.

\section{Conclusion}

The results of this study proved that high-dose rosuvastatin was better than conventional-dose rosuvastatin in improving blood lipid metabolism, reducing the inflammatory response, improving heart function, preventing and treating ventricular remodelling and myocardial fibrosis, indicating that high-dose rosuvastatin had stronger therapeutic effect on myocardial infarction and a better effect than conventional-dose rosuvastatin.

\section{Acknowledgments}

This study was supported by Zhongshan Hospital of Fudan University.

\section{Disclosure}

The authors declare no conflict of interest for this work.

\section{References}

1. Wu HB, Tian HP, Wang XC, et al. Clinical efficacy of ticagrelor in patients undergoing emergency intervention for acute myocardial infarction and its impact on platelet aggregation rate. Am J Transl Res. 2018;10(7):2175-2183.

2. Zimmermann S, Flachskampf FA, Alff A. Out-of-hospital cardiac arrest and percutaneous coronary intervention for ST-elevation myocardial infarction: long-term survival and neurological outcome. Int J Cardiol. 2013;166(1):236.

3. Shah N, Kelly AM, Cox N, et al. Myocardial Infarction in the "Young": risk Factors, Presentation, Management and Prognosis. Heart Lung Circ. 2016;25(10):955-960.

4. Bhatt AS, Ambrosy AP, Velazquez EJ. Adverse Remodeling and Reverse Remodeling After Myocardial Infarction. Curr Cardiol Rep. 2017;19(8):71.

5. Hofmann U, Frantz S. Role of lymphocytes in myocardial injury, healing, and remodeling after myocardial infarction. Circ Res. 2015;116(2):354-367. 
6. Chou R, Dana T, Blazina I, et al. Statins for Prevention of Cardiovascular Disease in Adults: evidence Report and Systematic Review for the US Preventive Services Task Force. JAMA. 2016;316 (19):2008-2024.

7. Oesterle A, Laufs U, Liao JK. Pleiotropic Effects of Statins on the Cardiovascular System. Circ Res. 2017;120(1):229-243.

8. Reddy R, Chahoud G, Mehta JL. Modulation of cardiovascular remodeling with statins: fact or fiction? Curr Vasc Pharmacol. 2005;3(1):69-79

9. Ridker PM, Danielson E, Fonseca FA, et al. Rosuvastatin to prevent vascular events in men and women with elevated C-reactive protein. N Engl J Med. 2008;359(21):2195-2207.

10. Bao JW, Sun B, Ma PP, et al. Rosuvastatin inhibits inflammatory response and resists fibrosis after myocardial infarction. Eur Rev Med Pharmacol Sci. 2018;22(1):238-245.

11. Taylor J. Third universal definition of myocardial infarction. Eur Heart J. 2012;33(20):2506-2507.

12. Banning AP, Baumbach A, Blackman D, et al. Percutaneous coronary intervention in the UK: recommendations for good practice 2015 Heart. 2015;101(Suppl 3):1-13.

13. Steg PG, James SK, Atar D, et al. ESC Guidelines for the management of acute myocardial infarction in patients presenting with ST-segment elevation. Eur Heart J. 2012;33:2569-2619.

14. Frangogiannis NG. Pathophysiology of Myocardial Infarction. Compr Physiol. 2015;5(4):1841-1875.

15. Reed GW, Rossi JE, Cannon CP. Acute myocardial infarction. Lancet. 2017;389(10065):197-210.

16. Adhyaru BB, Jacobson TA. Safety and efficacy of statin therapy. Nat Rev Cardiol. 2018;15(12):757-769.

17. Wang X, Zhao X, Li L, et al. Effects of Combination of Ezetimibe and Rosuvastatin on Coronary Artery Plaque in Patients with Coronary Heart Disease. Heart Lung Circ. 2016;25(5):459-465.

18. Kones R. Primary prevention of coronary heart disease: integration of new data, evolving views, revised goals, and role of rosuvastatin in management. A comprehensive survey. Drug Des Devel Ther. 2011;5:325-380.

19. Holmes MV, Millwood IY, Kartsonaki C, et al. Lipids, Lipoproteins, and Metabolites and Risk of Myocardial Infarction and Stroke. J Am Coll Cardiol. 2018;71(6):620-632.

20. Winter MP, Wiesbauer F, Blessberger H, et al. Lipid profile and long-term outcome in premature myocardial infarction. Eur J Clin Invest. 2018;48(10):e13008.

21. Nishikido T, Oyama J, Keida T, et al. High-dose statin therapy with rosuvastatin reduces small dense LDL and MDA-LDL: the Standard versus high-dose therApy with Rosuvastatin for lipiD lowering (SARD) trial. J Cardiol. 2016;67(4):340-346.

22. Paul S, Jellinger M, Handelsman Y, et al. American Association Of Clinical Endocrinologists And American College Of Endocrinology Guidelines For Management Of Dyslipidemia And Prevention Of Cardiovascular Disease. Endocr Pract. 2017;23(Suppl 2):1-87.

23. Toso A, Leoncini M, Maioli M, et al. Relationship Between Inflammation and Benefits of Early High-Dose Rosuvastatin on Contrast-Induced Nephropathy in Patients With Acute Coronary Syndrome: the Pathophysiological Link in the PRATO-ACS Study (Protective Effect of Rosuvastatin and Antiplatelet Therapy on Contrast-Induced Nephropathy and Myocardial Damage in Patients With Acute Coronary Syndrome Undergoing Coronary Intervention). JACC Cardiovasc Interv. 2014;7(12):1421-1429.
24. Golia E, Limongelli G, Natale F, et al. Inflammation and cardiovascular disease: from pathogenesis to therapeutic target. Curr Atheroscler Rep. 2014;16(9):435.

25. Pavlović M, Apostolović S, Stokanović D, et al. The Association between Galectin-3 and hs-CRP and the Clinical Outcome after Non-ST-Elevation Myocardial Infarction with Preexisting Atrial Fibrillation. Sci Rep. 2017;7(1):15106.

26. Zhang Y, Shao T, Yao L, et al. Effects of tirofiban on stent thrombosis, Hs-CRP, IL-6 and sICAM-1 after PCI of acute myocardial infarction. Exp Ther Med. 2018;16(4):3383-3388.

27. Inoue T, Kato T, Uchida T, et al. Local release of C-reactive protein from vulnerable plaque or coronary arterial wall injured by stenting. J Am Coll Cardiol. 2005;46(2):239-245.

28. Ridker PM, Lüscher TF. Anti-inflammatory therapies for cardiovascular disease. Eur Heart J. 2014;35(27):1782-1791.

29. Cen W, Chen Z, Gu N, et al. Prevention of AMI Induced Ventricular Remodeling: inhibitory Effects of Heart-Protecting Musk Pill on IL-6 and TNF-Alpha. Evid Based Complement Alternat Med. 2017;2017:3217395.

30. Lacerda L, Somers S, Opie LH, et al. Ischaemic Postconditioning Protects Against Reperfusion Injury via the SAFE. Pathway Cardiovasc Res. 2009;84(2):201-208.

31. Padró T, Cubedo J, Camino S, et al. Detrimental Effect of Hypercholesterolemia on High-Density Lipoprotein Particle Remodeling in Pigs. J Am Coll Cardiol. 2017;70(2):165-178.

32. Benson V, McMahon AC, Lowe HC. ICAM-1 in acute myocardial infarction: a potential therapeutic target. Curr Mol Med. 2007;7 (2):219-227.

33. Lawson C, Wolf S. ICAM-1 signaling in endothelial cells. Pharmacol Rep. 2009;61(1):22-32.

34. Iyer RP, Jung M, Lindsey ML. MMP-9 signaling in the left ventricle following myocardial infarction. Am J Physiol Heart Circ Physiol. 2016;311(1):H190-H198.

35. Nagase H, Visse R, Murphy G. Structure and function of matrix metalloproteinases and TIMPs. Cardiovasc Res. 2006;69(3):562-573.

36. Zavadzkas JA, Stroud RE, Bouges S, et al. Targeted overexpression of tissue inhibitor of matrix metalloproteinase-4 modifies post-myocardial infarction remodeling in mice. Circ Res. 2014;114 (9):1435-1445.

37. Spinale FG. Myocardial matrix remodeling and the matrix metalloproteinases: influence on cardiac form and function. Physiol Rev. 2007;87(4):1285-1342.

38. Chen YS, Gi WT, Liao TY, et al. Using the galectin-3 test to predict mortality in heart failure patients: a systematic review and meta-analysis. Biomark Med. 2016;10(3):329-342.

39. Li M, Yuan Y, Guo K, et al. Value of Galectin-3 in Acute Myocardial Infarction. Am J Cardiovasc Drugs. 2019;1:245.

40. Maries L, Manitiu I. Diagnostic and prognostic values of B-type natriuretic peptides (BNP) and N-terminal fragment brain natriuretic peptides (NT-pro-BNP). Cardiovasc J Afr. 2013;24(7):286-289.

41. van Kimmenade RR, Bakker JA, Crijns HJ, et al. The value of (NT-pro) BNP in the diagnosis, prognosis and treatment of congestive heart failure. Neth Heart J. 2004;12(2):61-63. 


\section{Publish your work in this journal}

Drug Design, Development and Therapy is an international, peerreviewed open-access journal that spans the spectrum of drug design and development through to clinical applications. Clinical outcomes, patient safety, and programs for the development and effective, safe, and sustained use of medicines are a feature of the journal, which has also been accepted for indexing on PubMed Central. The manuscript management system is completely online and includes a very quick and fair peer-review system, which is all easy to use. Visit http://www. dovepress.com/testimonials.php to read real quotes from published authors.

Submit your manuscript here: https://www.dovepress.com/drug-design-development-and-therapy-journal 